\title{
Stability of halocarbons in air samples stored in stainless- steel canisters
}

\author{
Tanja J. Schuck ${ }^{1}$, Ann-Katrin Blank ${ }^{1}$, Elisa Rittmeier ${ }^{1}$, Jonathan Williams ${ }^{2}$, Carl A. M. Brenninkmeijer ${ }^{2}$, \\ Andreas Engel ${ }^{1}$, and Andreas Zahn ${ }^{3}$ \\ ${ }^{1}$ Goethe University Frankfurt, Institute for Atmospheric and Environmental Sciences, Frankfurt, Germany \\ ${ }^{2}$ Max Planck Institute for Chemistry, Mainz, Germany \\ ${ }^{3}$ Karlsruhe Institute of Technology, Institute of Meteorology and Climate Research, Karlsruhe, Germany
}

Correspondence: Tanja J. Schuck (schuck@iau.uni-frankfurt.de)

Received: 2 July 2019 - Discussion started: 17 July 2019

Revised: 22 October 2019 - Accepted: 11 November 2019 - Published: 10 January 2020

\begin{abstract}
Measurements of halogenated trace gases in ambient air frequently rely on canister sampling followed by offline laboratory analysis. This allows for a large number of compounds to be analysed under stable conditions, maximizing measurement precision. However, individual compounds might be affected during the sampling and storage of canister samples. In order to assess halocarbon stability in whole-air samples from the upper troposphere and lowermost stratosphere, we performed stability tests using the high-resolution sampler (HIRES) air sampling unit, which is part of the Civil Aircraft for the Regular Investigation of the atmosphere Based on an Instrument Container (CARIBIC) instrument package. The HIRES unit holds 88 lightweight stainlesssteel cylinders that are pressurized in flight to 4.5 bar using metal bellows pumps. The HIRES unit was first deployed in 2010 but has up to now not been used for regular halocarbon analysis with the exception of chloromethane analysis. The sample collection unit was tested for the sampling and storage effects of 28 halogenated compounds. The focus was on compound stability in the stainless-steel canisters during storage of up to 5 weeks and on the influence of ozone, since flights take place in the upper troposphere and lowermost stratosphere with ozone mixing ratios of up to several hundred parts per billion by volume (ppbv). Most of the investigated (hydro)chlorofluorocarbons and long-lived hydrofluorocarbons were found to be stable over a storage time of up to 5 weeks and were unaltered by ozone being present during pressurization. Some compounds such as dichloromethane, trichloromethane, and tetrachloroethene started to decrease in the canisters after a storage time of
\end{abstract}

more than 2 weeks or exhibited lowered mixing ratios in samples pressurized with ozone present. A few compounds such as tetrachloromethane and tribromomethane were found to be unstable in the HIRES stainless-steel canisters independent of ozone levels. Furthermore, growth was observed during storage for some species, namely for HFC-152a, HFC23, and Halon 1301.

\section{Introduction}

Despite their low atmospheric mixing ratios of up to only a few hundred parts per trillion (ppt), halogenated trace gases have a significant impact on the earth's atmosphere. In particular, anthropogenic chlorinated and brominated halocarbons are responsible for stratospheric ozone depletion (Engel and Rigby, 2018). Of particular interest are the mixing ratios of such species in the upper troposphere as an entry point for chlorine and bromine into the stratosphere.

The trace gas composition in the upper troposphere and lowermost stratosphere (UTLS) can be analysed from aboard aircraft using in situ instrumentation or air sample collection followed by postflight analysis on the ground. Whereas fast in-flight measurements based on gas chromatography-mass spectrometry provide data of halocarbon and non-methane hydrocarbon mixing ratios in the UTLS at a higher spatial resolution (1-4 min; Apel et al., 2003; Sala et al., 2014; Bourtsoukidis et al., 2017), the number of species quantified is often limited and the instrumentation is complex. Although canister air sampling typically generates data at a much lower 
spatial coverage, the postflight analysis allows a wider range of substances to be measured. Thus, air sample collection is a well-established part of the scientific payload of both campaign-type studies such as the HIPPO (Wofsy, 2011) and ATTREX (Navarro et al., 2015; Jensen et al., 2017) projects and long-term projects such as CONTRAIL (Machida et al., 2008) and IAGOS-CARIBIC (Brenninkmeijer et al., 2007; Petzold et al., 2015).

The literature on compound stability in sampling canisters mainly deals with volatile organics. For example, Lerner et al. (2017) found alkanes and alkenes to be stable in electropolished stainless-steel canisters in a storage experiment over $4 \mathrm{~d}$, but the stability of oxygenated compounds was influenced by the level of humidity. The mixing ratios of aldehydes and monoterpenes were found to decrease significantly in stainless-steel cylinders even after short storage times of only a few days but exhibited extended stability in humidified cylinders (Batterman et al., 1998). In a storage experiment covering a period of up to $28 \mathrm{~d}$, Ochiai et al. (2002) found polar volatile organic compounds (VOCs) to be more stable at elevated relative humidities, while nonpolar VOCs were also stable in dry canisters. Better stability was found for VOCs in fused-silica-lined cylinders compared to electropolished stainless-steel cylinders (Ochiai et al., 2002; Hsieh et al., 2003).

The Civil Aircraft for the Regular Investigation of the atmosphere Based on an Instrument Container (CARIBIC) project (http://www.caribic-atmospheric.com/, last access date: 27 June 2019) investigates atmospheric composition from aboard a Lufthansa passenger aircraft equipped with a sophisticated air inlet system (Brenninkmeijer et al., 2007). CARIBIC is a long-term scientific project, employing a comprehensive set of instruments for performing simultaneous measurements of trace gases and aerosol particles inside a $1.5 \mathrm{t}$ airfreight container during regular long-distance flights of the aircraft. Measurement flights take place over 2-4 consecutive days 6-12 times per year. The instrument package consists of remote-sensing instruments, fast in situ instruments, and the collection of particulate matter and air samples (Brenninkmeijer et al., 2007; Petzold et al., 2015).

CARIBIC air sampling was initially limited to 28 glass flasks per series of flights. Taking advantage of the large spatial coverage of commercial long-distance flights, measurements from these CARIBIC glass flask samples have provided valuable information on the distribution of halogenated trace gases in the upper troposphere and lowermost stratosphere, for example regarding HFC-227ea (Laube et al., 2010), $\mathrm{SF}_{5} \mathrm{CF}_{3}$ (Sturges et al., 2012), perfluorocarbons (Laube et al., 2012), dichloromethane and other shortlived chlorocarbons (Leedham-Elvidge et al., 2015; Oram et al., 2017) and bromocarbons (Wisher et al., 2014), CFC114 (Laube et al., 2016), and CFC-113a (Adcock et al., 2018). Complementing the two existing sampling units with glass cylinders, the new high-resolution sampler (HIRES) unit with 88 stainless-steel cylinders was built in 2010 for the automated collection of whole-air samples at a higher frequency (Schuck et al., 2012). Since then it has been regularly employed for analysis of the greenhouse gases $\mathrm{CO}_{2}$, $\mathrm{CH}_{4}, \mathrm{~N}_{2} \mathrm{O}$, and $\mathrm{SF}_{6}$ and for the analysis of non-methane hydrocarbons (Baker et al., 2016; Li et al., 2018), but it has not been used for dedicated measurements of halogenated trace gases.

Measurements of halocarbons in the tropopause region are sparse. CARIBIC air samples are collected on a regular basis and therefore complement measurements from research aircraft campaigns such as the ATTREX project (Navarro et al., 2015) or the TACTS, WISE, and PGS projects (Keber et al., 2019). In order to explore the potential of the HIRES unit for halocarbon measurements, we intensively tested the sampling unit in a series of laboratory experiments. In particular, we investigated the stability of 28 compounds during storage between sampling and analysis over typical processing times. In addition, we investigated the influence of ozone, which may affect sampling of reactive species in the lowermost stratosphere. Because the test series included storage of the sampling unit over several weeks, and because different tests were performed, it is not possible to carry out such experiments between the regularly scheduled research flights of the CARIBIC container. This would have caused an unacceptably long grounding of all the instrumentation because for reasons of aircraft certification the air sampler has to be part of the instrument package during each flight. Therefore, we took the opportunity of a longer operational break for CARIBIC flights in 2016.

\section{Technical details}

\subsection{The high-resolution sampler}

The HIRES unit holds 88 lightweight cylinders made of stainless steel (wall thickness $0.25 \mathrm{~mm}$ ), each with a volume of $1 \mathrm{~L}$, and its total weight is $43 \mathrm{~kg}$. Samples are pressurized to 4.5 bar in flight at preset time intervals using two metal bellows pumps (Senior Aerospace Metal Bellows, 28823-7). Coarse particles are filtered by a $2 \mu$ filter (Swagelok SS4F-2). Each cylinder is connected to one of six 16-position valves (Valco, EMT4LSD16MWE) by which the samples are selected. In a laboratory setting, up to six samples can be pressurized simultaneously with identical air mixtures. Figure 1 shows a schematic view of the cylinders and valves.

Before a flight, the HIRES unit undergoes leak testing with ambient air passed through a $10 \mathrm{X}$ molecular sieve ( $8 \AA$ pore diameter) to prevent contamination of tubing with hydrocarbons. Cylinders are not preconditioned. On take-off, cylinders will usually hold remnant air from the last research flight or from the leak test. The reason is that due to the mechanical stability of the thin-walled flasks they should not be evacuated to absolute pressures below 600 mbar. Tests during the construction phase and monitoring based on NMHC mea- 


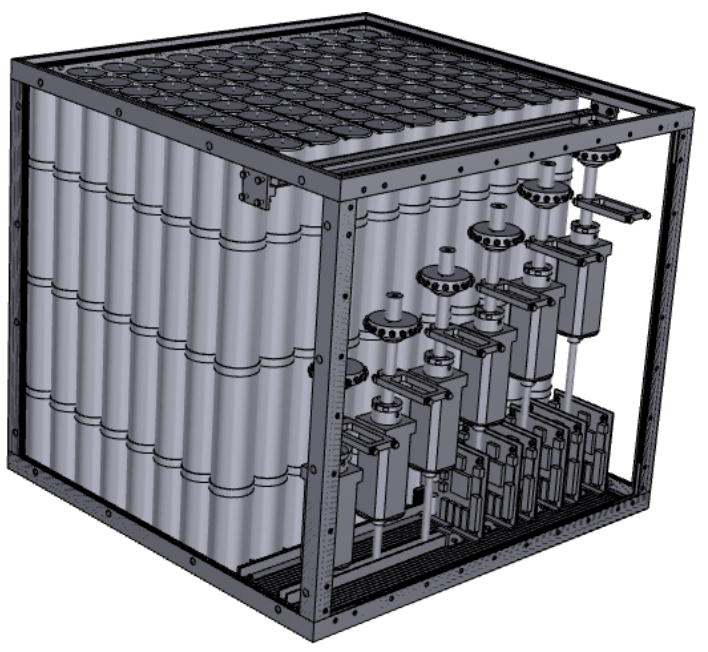

Figure 1. Schematic view of the 88 sample cylinders inside the HIRES unit and the six multiposition valves. For simplicity all tubing is omitted to illustrate only the positioning of these main components. Drawing: Laurin Merkel.

surements during the sampler's first years of operation have shown that eight iterations of flushing reliably dilute remnants of previous fillings of tropospheric air. In flight, canisters are therefore flushed with ambient air eight times; this is achieved by filling a flask to 4 bar followed by venting for $20 \mathrm{~s}$. After this time, ambient pressure is reached, which aboard the aircraft at flight altitude is $\sim 700 \mathrm{mbar}$. After that, canisters are eventually pressurized to 4.5 bar. The total time needed for this procedure is $\sim 4 \mathrm{~min}$, of which $10-20 \mathrm{~s}$ is the final pressurization. During each flushing about $20 \%$ of the air from the previous filling remains in the sample canister. Depending on ambient pressure, $70 \%-80 \%$ of the air is from the final pressurization stage. The sampling period is defined as the time interval during which at least $97 \%$ of the sample air was collected. This comprises the last three of the eight flushing iterations and the final pressurization stage, adding up to a total sampling time of 1-2 min. Data from continuously measuring instruments, measuring variables such as ozone $\left(\mathrm{O}_{3}\right)$ (Zahn et al., 2012) and carbon monoxide (CO) (Scharffe et al., 2012), are integrated over the sampling intervals for comparison with canister measurements.

Upon the return of the instrument container, the sample collector is retrieved and postflight gas chromatography analyses for greenhouse gases (Schuck et al., 2009) and nonmethane hydrocarbons (Baker et al., 2010) are performed in the laboratory. If a halocarbon analysis is performed, it is usually last in a series of measurements and takes place approximately 3 to 5 weeks after the flight. The duration of the long-term storage test time of 8 weeks was deliberately chosen to be beyond this period.

\subsection{Halocarbon measurements}

The halocarbon measurements are based on adsorptiondesorption gas chromatography-mass spectrometry (GCMS) (Hoker et al., 2015; Schuck et al., 2018). As halocarbon mixing ratios in the atmosphere are in the parts per trillion range, preconcentration of the sample air prior to gaschromatographic separation and detection is required (Obersteiner et al., 2016). In addition, the sample air is dried by passing over a heated $\left(80^{\circ} \mathrm{C}\right)$ tube filled with magnesium perchlorate, $\mathrm{Mg}\left(\mathrm{ClO}_{4}\right)_{2}$. Mixing ratios are therefore reported as dry mole fractions. All tubing is heated to avoid the condensation of moisture (relevant to the HIRES unit only for tropospheric samples) and to minimize wall losses. After drying, the sample flow is directed through a $1 / 16 \mathrm{in}$. stainless-steel sample loop (inner diameter $1 \mathrm{~mm}$ ) filled with HayeSep D over a length of $10 \mathrm{~cm}$. During the adsorption phase the sample loop is kept at $-80^{\circ} \mathrm{C}$ (Stirling cooler, Global Cooling, M150). Depending on the pressure of the HIRES air samples at the time of measurement, the enrichment flow is set to either 100 or $150 \mathrm{~mL} \mathrm{~min}^{-1}$, controlled by a mass flow controller mounted behind the sample loop in order to exclude sample contamination from the controller. The enriched sample volume is determined by monitoring the pressure inside a $2 \times 2 \mathrm{~L}$ reference volume which is evacuated prior to sample enrichment. Typically a volume of $0.8-1.0 \mathrm{~L}$ of air is used. For desorption, the sample loop is heated to approximately $200^{\circ} \mathrm{C}$ for $4 \mathrm{~min}$ while the carrier gas flow is directed through it (helium grade 6.0 (Praxair), VICI Valco HP2 purification system).

Gas chromatography (GC) is performed with an Agilent $7890 \mathrm{~A}$ instrument equipped with a $7.5 \mathrm{~m}$ precolumn and a $22.5 \mathrm{~m}$ main column (both GasPro PLOT, inner diameter $0.32 \mathrm{~mm}$ ). The temperature programme of the GC starts at $50^{\circ} \mathrm{C}$; this temperature is maintained for $2 \mathrm{~min}$ after which the oven is heated to $95^{\circ} \mathrm{C}$ at a rate of $15^{\circ} \mathrm{C} \mathrm{min}^{-1}$. Then it is heated to $135^{\circ} \mathrm{C}$ at $10^{\circ} \mathrm{C} \mathrm{min}^{-1}$ and finally to $200^{\circ} \mathrm{C}$ at a rate of $22^{\circ} \mathrm{C} \mathrm{min}^{-1}$. This temperature is maintained for another $2.95 \mathrm{~min}$. The complete runtime adds up to $17.95 \mathrm{~min}$. Backward flushing of the precolumn is started after $12.6 \mathrm{~min}$ to avoid contamination of the subsequent chromatographic run with high-boiling substances. Mass spectrometric detection is carried out with a quadrupole mass spectrometer (QPMS; Agilent 5975C) in selected-ion-monitoring mode, which scans preselected masses at a given retention time. Ionization takes place via electron impact at $70 \mathrm{eV}$. Data from a time-offlight mass spectrometer operated in parallel with the QP-MS are not discussed here. The experimental setup was described in more detail by Hoker et al. (2015) and Obersteiner et al. (2016).

HIRES samples are measured relative to a laboratory standard which was collected cryogenically at Jungfraujoch (Switzerland) in December 2007. This standard is compared monthly to a tertiary standard of the Advanced Global Atmospheric Gases Experiment (AGAGE) network and was 
recalibrated versus several AGAGE standards in December 2018. Drift of the working standard can thus be excluded. Mixing ratios are reported in parts per trillion on Scripps Institution of Oceanography (SIO) scales except for trichloroethene, dibromochloromethane, tetrachloroethene, and tribromomethane (reported on scales defined by the University of Bristol (UK), the University of East Anglia (UK), and the National Oceanic and Atmospheric Administration (US)). Mixing ratios of $\mathrm{CO}$ and ozone from CARIBIC inflight measurements are reported in parts per billion by volume (ppbv). Details of the respective calibration of both instruments have been published by Scharffe et al. (2012) and Zahn et al. (2012).

\subsection{Storage experiments}

To test a possible influence of ozone on reactive halocarbon species, HIRES sample canisters were pressurized in the laboratory with a mixture of a well-characterized laboratory standard and synthetic air. The standard was filled with an oil-free compressor at Taunus Observatory $\left(50.22^{\circ} \mathrm{N}\right.$, $8.44^{\circ} \mathrm{E}, 825 \mathrm{~m}$ a.s.1.) in 2015 and contained typical tropospheric mixing ratios of halocarbons. During pressurization it had been dried using magnesium perchlorate. This standard was chosen for the storage experiments, as air from the UTLS usually contains water vapour mixing ratios of less than 100 ppmv.

Figure 2 shows the setup used for the pressurization of the HIRES unit for storage tests. Samples could be filled with the standard gas, synthetic air, or a mixture of both. Contrary to the setup in flight, when the HIRES cylinders are filled with ambient air pressurized by the metal bellows pumps, in this setup they are pressurized directly from high-pressure gas cylinders. On path I the synthetic-air flow passed a quartz glass tube exposed to UV light from a mercury lamp generating ozone. On average, $\sim 1200 \mathrm{ppbv}$ of ozone was generated, as determined by a separate measurement (using a T400 API photometric ozone analyser), but it was not monitored during the filling of the cylinders. After mixing of the ozone-enriched synthetic air with the standard gas (path III), ozone mixing ratios were approximately $400-600 \mathrm{ppbv}$, being characteristic of the lowermost stratosphere as typically sampled by the CARIBIC aircraft. This procedure was chosen because generating ozone directly in the flow of the standard gas could have altered the mixing ratios of the reactive halogenated compounds contained in the standard.

For a short-term storage test, six individual canisters were pressurized consecutively to an absolute pressure of $4 \mathrm{bar}$, using 1.7 bar of synthetic air and 2.3 bar of the standard gas. For three of the canisters, the synthetic air was enriched in ozone by directing its flow via the UV lamp. All samples were analysed $1 \mathrm{~d}$ after filling and again 1 week later.

Because of the large number of cylinders, measurement of all the samples of one CARIBIC flight series takes several days, depending on the type of analysis performed. The halocarbon measurements described here add up to approximately $53 \mathrm{~h}$ total measurement time, not including blank measurements and preparation work. In addition, the HIRES unit needs to circulate between different laboratories in different institutions; therefore, the time between in-flight sampling and postflight sample analyses can be much longer than 1 week.

Canisters have a volume of $1 \mathrm{~L}$ and were pressurized up to 4 bar. Due to the mechanical stability of the thin-walled flasks, they may not be evacuated during the measurement. For a corresponding long-term storage test with six measurements of one gas mixture, the sample volume of one cylinder would not be sufficient. Therefore, six cylinders were simultaneously filled, and on each measurement day the next canister of such a series was measured. Canisters were pressurized to an absolute pressure of 4 bar with one of the following gas mixtures:

- synthetic air (4 bar);

- synthetic air (1 bar) and standard (3 bar);

- synthetic air (1.7 bar) and standard (2.3 bar);

- synthetic air (1.7 bar), ozone, and standard (2.3 bar); and

- synthetic air (4 bar) and ozone.

Two subsets of six canisters each were pressurized simultaneously with each of the mixtures, thus giving two subsets with identical composition. One canister from each subset was analysed after a storage time of 1, 8, 15, 29, 51, and $57 \mathrm{~d}$. The full measurement series for the long-term storage test comprises analyses of 60 individual canisters. Between measurements, the sampling unit was stored in an air-conditioned laboratory at temperatures of around $22^{\circ} \mathrm{C}$. The air conditioning uses water and is therefore not expected to adversely influence halocarbon analysis.

Assuming the synthetic air to be free of any of the compounds of interest, mixing ratios in the canisters should be identical to the original mixing ratios weighted by the relative contribution of each gas; i.e., trace gas mixing ratios in the HIRES canisters should be about $75 \%$ of the original mixing ratios of the standard in the case of 1 bar of synthetic air mixed with 3 bar of the standard gas and about $57.5 \%$ in the case of 1.7 bar of synthetic air mixed with 2.3 bar of the standard gas. Measurements of the pure synthetic air, however, revealed contamination of the synthetic air with carbonyl sulfide (12.8 ppt), chloromethane (24.3 ppt), HFC$152 \mathrm{a}(2.8 \mathrm{ppt})$, and tetrachloroethene $(1.1 \mathrm{ppt})$. This needs to be taken into account for the calculation of the trace gas mixing ratios expected in the HIRES canisters after mixing synthetic air and standard gas. To reduce uncertainties related to the mixing of synthetic air and standard gas, which are mainly caused by the uncertainty of the pressure readings of approximately 0.1 bar, all compounds were evaluated relative to $\mathrm{CFC}-12\left(\mathrm{CCl}_{3} \mathrm{~F}\right)$. CFC-12 was found to be stable in the canisters. 


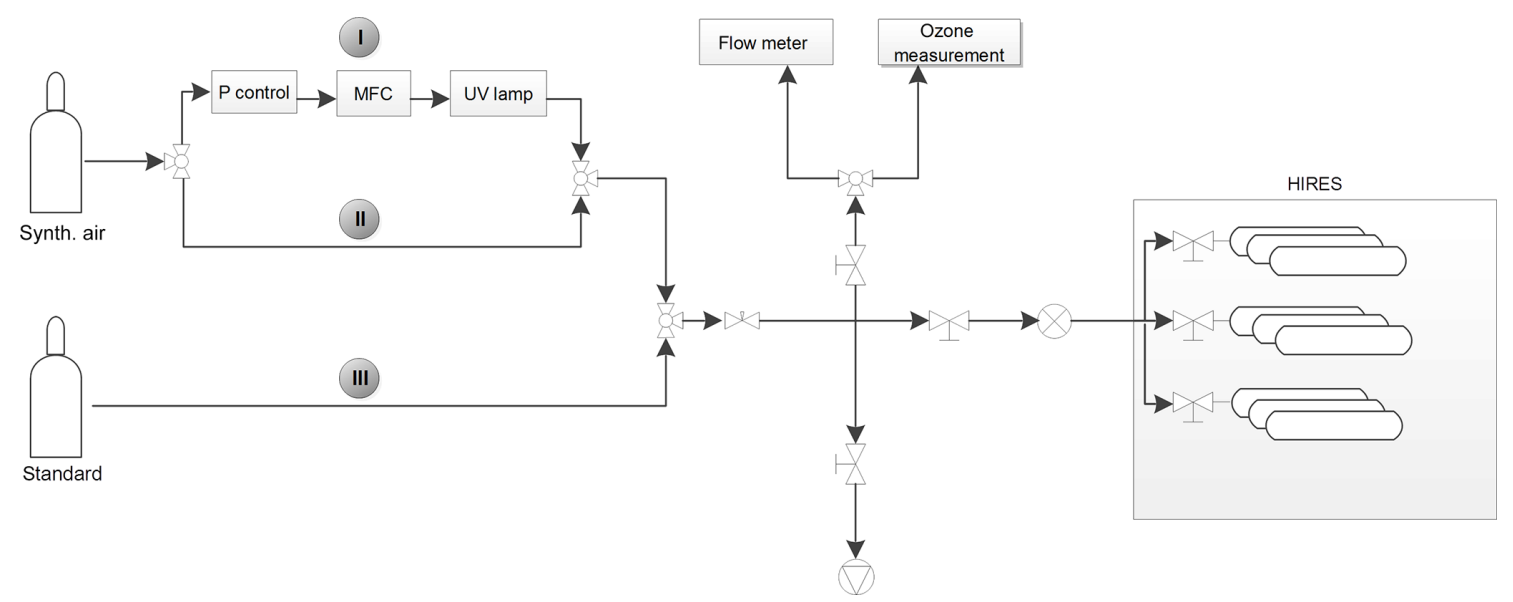

Figure 2. Schematic view of the gas flows for filling HIRES canisters for the storage experiments. Samples can be pressurized with either pure air from a standard gas bottle (flow path III), pure synthetic air (path II), or with a mixture of both. Alternatively, the flow of synthetic air can be directed to pass an ozone-generating UV lamp (path I).

\section{Results}

\subsection{Ozone interference and short-term stability}

The short-term storage test was performed to investigate the influence of ozone being present during pressurization. The HIRES unit is usually operated in the UTLS region and ozone mixing ratios are commonly up to $800 \mathrm{ppbv}$, depending on flight route and season. Figure 3 shows as examples the results of the test for HFC-134a $\left(\mathrm{CH}_{2} \mathrm{FCF}_{3} ; \mathrm{Fig} 3 \mathrm{a}\right)$ and dichloromethane $\left(\mathrm{CH}_{2} \mathrm{Cl}_{2} ; \mathrm{Fig} 3 \mathrm{~b}\right)$. The ratio of the mixing ratio of the respective substance to $\mathrm{CFC}-12\left(\mathrm{CCl}_{3} \mathrm{~F}\right)$ as described in the previous section is plotted. The solid black line represents the value expected from the known mixing ratios of the standard gas. For each measurement day, a daily precision value was calculated from the variability of the measurements of the standard. This expected daily uncertainty range is represented by the grey error bars. Solid coloured lines stand for canisters pressurized with synthetic air not treated by the UV lamp, and dashed coloured lines represent canisters pressurized with the synthetic air passing the UV lamp and thus with ozone present. Error bars for the individual data points are not shown as they overlap and merge into one indistinguishable error bar. However, if the symbols fall within the uncertainty range indicated by the grey error bars of the expected value, this means that they agree within $2 \sigma$ with the expected value.

For HFC-134a, the ratio of its mixing ratio to that of CFC-12 agrees with the expected value within the experimental uncertainty range on both the first and eighth day. For dichloromethane, samples influenced by ozone (dashed lines) show a significantly lower ratio to CFC-12 than expected. No systematic change from day one to day eight was measured for either of the two compounds. While dichloromethane was stable over a storage time of 1 week, it was influenced by ozone and already exhibited depleted mixing ratios in the canisters $1 \mathrm{~d}$ after pressurization. It can thus not be reliably measured using HIRES canisters from the lowermost stratosphere.

The substances that were found to be depleted in HIRES canisters when pressurized in the presence of ozone were dichloromethane $\left(\mathrm{CH}_{2} \mathrm{Cl}_{2}\right)$, trichloroethene $\left(\mathrm{C}_{2} \mathrm{HCl}_{3}\right)$, tetrachloroethene $\left(\mathrm{C}_{2} \mathrm{Cl}_{4}\right)$, and dibromochloromethane $\left(\mathrm{CHBr}_{2} \mathrm{Cl}\right)$. Carbonyl sulfide (COS) showed higher mixing ratios in samples that had been exposed to ozone. While there is clear evidence that the mixing ratios of these substances are modified in the canisters when they are pressurized at elevated levels of ozone, it is not possible from these experiments to deduce an ozone threshold above which results become unreliable. We will thus consider all UTLS samples from the current HIRES unit that are characterized as stratospheric either by ozone mixing ratios above the respective ozone chemical tropopause, by potential vorticity, or by low mixing ratios of nitrous oxide as not suitable for the postflight analysis of the above-mentioned compounds.

It should, however, be noted that the experiment does not adequately mimic stratospheric conditions. In the laboratory tests presented here, the reference gas is mixed with the ozone-enriched synthetic air during the filling procedure. In flight, stratospheric air masses with high ozone levels will be in some state of mixing and continuously chemically processing. In addition, contact with hot surfaces, such as inside the metal bellows pumps, will destroy ozone.

Among the substances influenced by ozone, dibromochloromethane $\left(\mathrm{CHBr}_{2} \mathrm{Cl}\right)$ additionally showed decreasing mixing ratios after only 1 week of storage (depleted by $94 \%)$, while bromomethane $\left(\mathrm{CH}_{3} \mathrm{Br},+46 \%\right)$ and chloromethane $\left(\mathrm{CH}_{3} \mathrm{Cl},+14 \%\right)$ were found to grow. Trichloroethene $\left(\mathrm{C}_{2} \mathrm{HCl}_{3}\right)$ exhibited a variability which did not allow for stringent conclusions to be drawn in the short- 

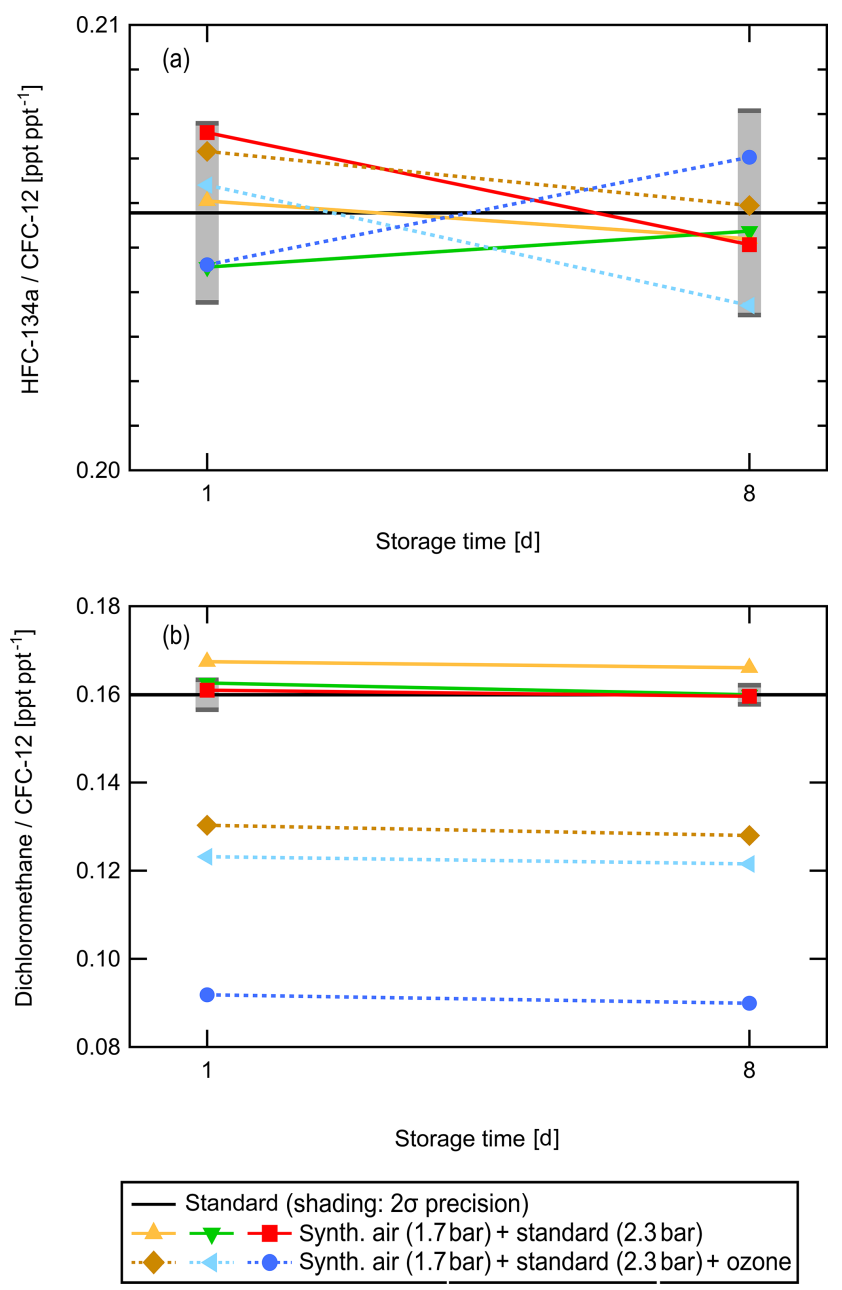

Figure 3. Results of the ozone and short-term storage test for HFC134a (a) and dichloromethane (b). The ratio of mixing ratios of the respective compound relative to that of $\mathrm{CFC}-12$ to cancel dilution uncertainties is shown. The solid black line represents the value expected from direct measurements of the standard gas and the synthetic air. Grey shading indicates the $2 \sigma$ experimental uncertainty range around the expected value; error bars of individual data points are omitted for clarity. Colours represent different canisters filled with the gas mixture indicated in the legend; each canister was measured twice, i.e., $1 \mathrm{~d}$ after pressurization and again after $8 \mathrm{~d}$ of storage.

term storage test. Tribromomethane $\left(\mathrm{CHBr}_{3}\right)$, which was unaffected by ozone, was depleted by $70 \%$ after 1 week of storage. Table 1 summarizes these results.

\subsection{Long-term stability}

The long-term storage test comprised measurements of pressurized canisters after storage times of 1, 8, 15, 29, 51, and $57 \mathrm{~d}$. While for the short-term test individual canisters were measured on day one and day eight, this was not possible for the long-term test. For the long-term test, six cylinders were simultaneously filled, and on each measurement day the next canister in the series was measured. Thus, it cannot be fully excluded that stability might not only depend on the substance investigated, but it might be a feature of an individual canister, for example related to the quality of welding seams.

Figure 4 shows, as an example, results of the long-term storage test for HFC-134a, dichloromethane, and HFC-152a. As before, the ratio of the mixing ratio of the respective substance to that of CFC-12 is shown. The black line indicates the expected ratio and the grey shaded area represents the experimental $2 \sigma$ uncertainty range. Solid lines represent measurements of the gas mixture without ozone, and dashed lines represent those with ozone. Error bars for individual data points are not shown. Like most long-lived halogenated tracers, HFC-134a variability is smaller than the measurement precision, and measured mixing ratios agree within $2 \sigma$ with the expected value.

Some substances that were found to be stable during the 1-week short-term test decreased after longer storage times, for example dichloromethane, shown in Fig. 4b. A similar behaviour was observed for trichloromethane $\left(\mathrm{CHCl}_{3}\right)$, tetrachloromethane $\left(\mathrm{CCl}_{4}\right)$, trichloroethene $\left(\mathrm{C}_{2} \mathrm{HCl}_{3}\right)$, tetrachloroethene $\left(\mathrm{C}_{2} \mathrm{Cl}_{4}\right)$, tribromomethane $\left(\mathrm{CHBr}_{3}\right)$, and bromochloromethane $\left(\mathrm{CH}_{2} \mathrm{BrCl}\right)$. Measurements of these compounds from the HIRES canisters should not be evaluated if analysis takes place more than 2 weeks after sample collection, as the long-term test indicates changes of mixing ratios start to occur after that period. In general, the decrease during long-term storage seems to be independent of the influence of ozone although the gas mixture that showed the largest depletion did contain ozone. Ozone could not be monitored during the pressurization of the samples. It can therefore not be excluded that the two gas mixtures represented by dashed lines in Fig. 4 may have been exposed to different amounts of ozone.

Figure $4 \mathrm{c}$ shows the result of the long-term storage test for HFC-152a $\left(\mathrm{CH}_{3} \mathrm{CHF}_{2}\right)$. While mixing ratios measured on days one and eight were within the expected range, they started to significantly increase after storage day 15 . This also occurred for samples influenced by ozone, independent of the gas mixture. A similar result was found for Halon 1301 $\left(\mathrm{CBrF}_{3}\right)$ and HFC-23 $\left(\mathrm{CHF}_{3}\right)$. HFC-23 is known to degas from certain materials; thus degassing from valve seals might be a possible source. The rotors of the Valco multiposition valves are made of Valcon E, a polyaryletherketone-PTFE composite; therefore, degassing of fluorinated compounds could occur. Of the shorter-lived compounds investigated, bromomethane $\left(\mathrm{CH}_{3} \mathrm{Br}\right)$ exhibited an increase in the longterm storage experiment. Table 1 summarizes the results of the long-term and the short-term tests. 

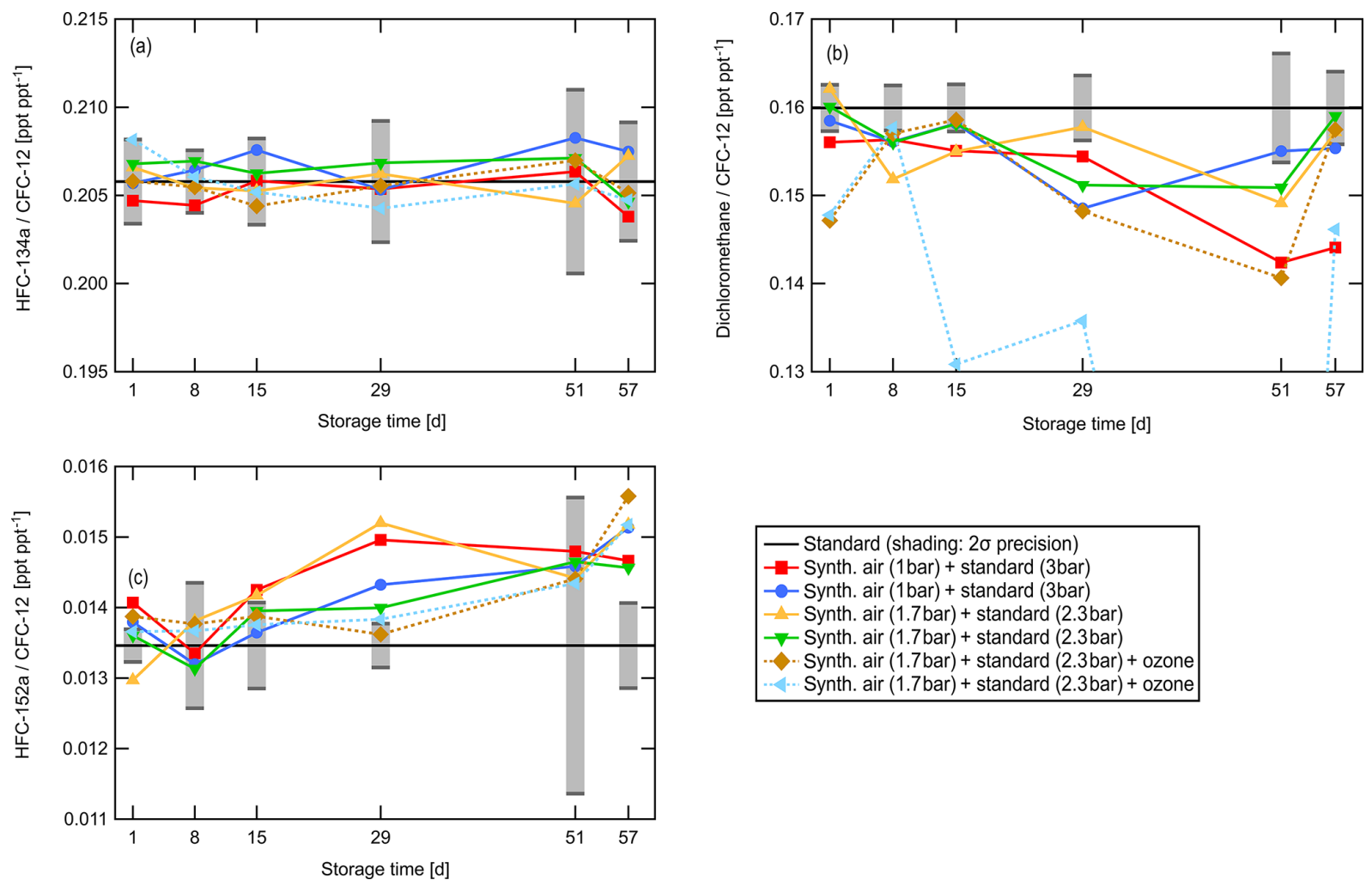

Figure 4. Results of the ozone and long-term storage test for HFC-134a (a), dichloromethane (b), and HFC-152a (c). The ratio of the mixing ratio of the respective compound relative to that of CFC-12 to cancel dilution uncertainties is shown. For dichloromethane the vertical scale has been adjusted, cutting off samples that were strongly depleted. The solid black line represents the value expected from direct measurements of the standard gas and the synthetic air. Shading indicates the $2 \sigma$ experimental uncertainty range around the expected value; error bars of individual data points are omitted for clarity. Colours represent groups of canisters which were simultaneously filled with the gas mixture indicated in the legend. On each measurement day, one canister in each group was analysed.

\subsection{Air samples from the UTLS}

As an example of air collected in the atmosphere under real conditions, samples from CARIBIC flight 544, which took place on 22 March 2018 travelling from Munich (Germany) to Denver (US), were analysed. These measurements were performed approximately 5 weeks after the flight; thus only substances that were shown to be stable in the long-term stability experiment are expected to yield reliable results. Figure 5 shows a time series of ozone; CFC-12, which was found to be stable in all experiments; and dichloromethane, which was found to be depleted in samples pressurized at elevated ozone mixing ratios and decreased with storage time.

CFC-12 anticorrelates with mixing ratios of ozone, and this is also found for the other long-lived compounds which were stable in the storage experiments. Such a behaviour is expected, because ozone-rich stratospheric air masses are aged and should contain lower mixing ratios depending on a substance's stratospheric lifetime and transport pathway. Three of the canisters analysed from this flight were collected in tropospheric air masses characterized by lower mixing ratios of ozone levels. Mixing ratios of CFC-12 mea- sured in these samples are around $510 \mathrm{ppt}$, which is consistent with current tropospheric mixing ratios observed at ground sites (Schuck et al., 2018). Similarly consistent numbers are measured for the other compounds expected to be stable in the canisters according to the storage experiments.

Dichloromethane mixing ratios are below $1 \mathrm{ppt}$ in most samples, which is close to the $0.4 \mathrm{ppt}$ limit of detection as derived from the 3-fold noise level. Only three samples have mixing ratios above $5 \mathrm{ppt}$; they are at the same time characterized by higher mixing ratios of CFC-12 and low mixing ratios of ozone, which is indicative of tropospheric air. Leedham-Elvidge et al. (2015) reported stratospheric dichloromethane mixing ratios measured from glass samples collected during CARIBIC flights in 2001-2002, 20092010, and 2011-2012 to vary from around 5 to around 35 ppt. The mixing ratios measured from the HIRES stainless-steel cylinders of CARIBIC flight 544 are significantly lower, which is consistent with the storage test results. A similar behaviour was found for all compounds which were not stable in the storage tests.

In the tropospheric air samples, dichloromethane varied between 14 and $49 \mathrm{ppt}$. These mixing ratios agree with mix- 
Table 1. Results of short-term ( $8 \mathrm{~d}$ ) storage test, long-term $(57 \mathrm{~d})$ storage test, and ozone interference. " $X$ " indicates that substances were found to be stable in the respective storage test, and arrows indicate whether mixing ratios were increasing $(\nearrow)$ or decreasing $(\searrow)$. Numbers indicate the maximum deviation measured for substances not stable in HIRES cylinders.

\begin{tabular}{|c|c|c|c|c|}
\hline Substance & & Stable short-term & Stable long-term & Influenced by $\mathrm{O}_{3}$ \\
\hline CFC-12 & $\mathrm{CCl}_{2} \mathrm{~F}_{2}$ & $\mathrm{X}$ & $\mathrm{X}$ & \\
\hline CFC-11 & $\mathrm{CCl}_{3} \mathrm{~F}$ & $\mathrm{X}$ & $\mathrm{X}$ & \\
\hline HCFC-22 & $\mathrm{CHClF}_{2}$ & $\mathrm{X}$ & $\mathrm{X}$ & \\
\hline HCFC-141b & $\mathrm{CH}_{3} \mathrm{CCl}_{2} \mathrm{~F}$ & $\mathrm{X}$ & $\mathrm{X}$ & \\
\hline HCFC-142b & $\mathrm{CH}_{3} \mathrm{CClF}_{2}$ & $\mathrm{X}$ & $\mathrm{X}$ & \\
\hline HFC-125 & $\mathrm{CHF}_{2} \mathrm{CF}_{3}$ & $\mathrm{X}$ & $\mathrm{X}$ & \\
\hline HFC-134a & $\mathrm{CH}_{2} \mathrm{FCF}_{3}$ & $\mathrm{X}$ & $\mathrm{X}$ & \\
\hline HFC-143a & $\mathrm{CH}_{3} \mathrm{CF}_{3}$ & $\mathrm{X}$ & $\mathrm{X}$ & \\
\hline HFC-152a & $\mathrm{CH}_{3} \mathrm{CHF}_{2}$ & $\mathrm{X}$ & $\nearrow(16 \%)$ & \\
\hline HFC-23 & $\mathrm{CHF}_{3}$ & $\mathrm{X}$ & $\nearrow(15 \%)$ & \\
\hline HFC-227ea & $\mathrm{CF}_{3} \mathrm{CHFCF}_{3}$ & $\mathrm{X}$ & $\mathrm{X}$ & \\
\hline HFC-245fa & $\mathrm{CHF}_{2} \mathrm{CH}_{2} \mathrm{CF}_{3}$ & $\mathrm{X}$ & $\mathrm{X}$ & \\
\hline HFC-32 & $\mathrm{CH}_{2} \mathrm{~F}_{2}$ & $\mathrm{X}$ & $\mathrm{X}$ & \\
\hline Halon 1211 & $\mathrm{CBrClF}_{2}$ & $\mathrm{X}$ & $\mathrm{X}$ & \\
\hline Halon 1301 & $\mathrm{CBrF}_{3}$ & $\mathrm{X}$ & $\nearrow(5 \%)$ & \\
\hline Halon 2402 & $\mathrm{C}_{2} \mathrm{Br}_{2} \mathrm{~F}_{4}$ & $\mathrm{X}$ & $X$ & \\
\hline Chloromethane & $\mathrm{CH}_{3} \mathrm{Cl}$ & $\nearrow$ & $\nearrow(14 \%)$ & \\
\hline Dichloromethane & $\mathrm{CH}_{2} \mathrm{Cl}_{2}$ & $\mathrm{X}$ & $\searrow(-77 \%)$ & $\searrow$ \\
\hline Trichloromethane & $\mathrm{CHCl}_{3}$ & $\mathrm{X}$ & $(-97 \%)$ & $\searrow$ \\
\hline Tetrachloromethane & $\mathrm{CCl}_{4}$ & $\searrow$ & $\searrow(-47 \%)$ & \\
\hline 1,1,1-Trichloroethane & $\mathrm{CCl}_{3} \mathrm{CH}_{3}$ & $\mathrm{X}$ & $\mathrm{X}$ & \\
\hline Trichloroethene & $\mathrm{C}_{2} \mathrm{HCl}_{3}$ & $\searrow$ & $\searrow(-97 \%)$ & $\searrow$ \\
\hline Tetrachloroethene & $\mathrm{C}_{2} \mathrm{Cl}_{4}$ & $\mathrm{x}$ & $(-97 \%)$ & $\searrow$ \\
\hline Bromomethane & $\mathrm{CH}_{3} \mathrm{Br}$ & $\nearrow$ & $\nearrow(46 \%)$ & \\
\hline Tribromomethane & $\mathrm{CHBr}_{3}$ & $\searrow$ & $\searrow(-93 \%)$ & \\
\hline Bromochloromethane & $\mathrm{CH}_{2} \mathrm{BrCl}$ & $\mathrm{X}$ & $(-45 \%)$ & \\
\hline Dibromochloromethane & $\mathrm{CHBr}_{2} \mathrm{Cl}$ & $\searrow$ & $\searrow(-88 \%)$ & $\searrow$ \\
\hline Carbonyl sulfide & OCS & $\mathrm{X}$ & $\nearrow(20 \%)$ & $\pi$ \\
\hline Sulfuryl fluoride & $\mathrm{SO}_{2} \mathrm{~F}_{2}$ & $\mathrm{X}$ & $X$ & \\
\hline
\end{tabular}

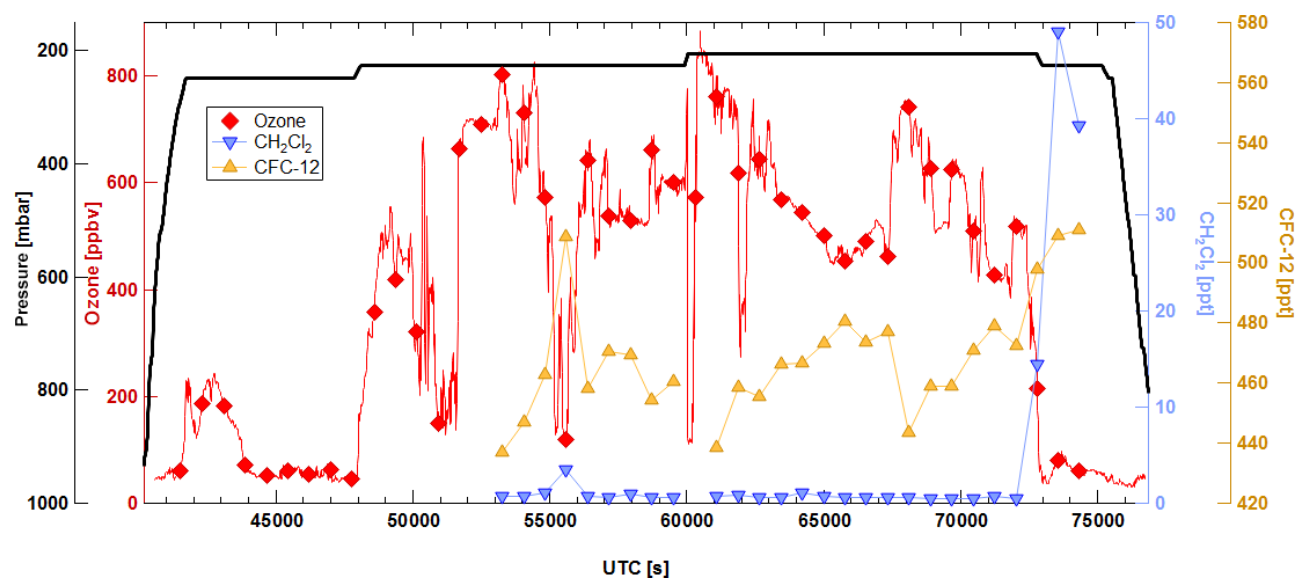

Figure 5. Time series of ozone (red), CFC-12 (yellow), and dichloromethane (blue) during a flight from Munich to Denver on 22 March 2018. Ozone high-resolution data represented by the red line are integrated over the sampling period of each whole-air sample (red diamonds). 
ing ratios in tropospheric samples in the dataset presented by Leedham-Elvidge et al. (2015), which were up to $65 \mathrm{ppt}$ with an increase observed from 2006 to 2012, but they are somewhat lower than mixing ratios on the ground in March 2018 (Schuck et al., 2018). This is consistent with the result from the storage test that dichloromethane is not stable in HIRES cylinders in the long term.

Figures 6 and 7 show correlations of CFC-12, HFC-134a, and dichloromethane with ozone and $\mathrm{CO}$, respectively. For the stable long-lived compounds CFC-12 and HFC-134a, a tight correlation with ozone $\left(r^{2}=0.98\right.$ and $\left.r^{2}=0.99\right)$ and with $\mathrm{CO}\left(r^{2}=0.80\right.$ and $\left.r^{2}=0.79\right)$ is found. For one tropospheric sample, there is no corresponding integrated CO mixing ratio, because it was collected during one of the regular in-flight calibration phases of the $\mathrm{CO}$ instrument.

Dichloromethane does not correlate with ozone or with $\mathrm{CO}$ in the stratosphere (Figs. 6c and 7c), but it does show a correlation with $\mathrm{CO}$ for samples with $\mathrm{CO}$ mixing ratios of more than $40 \mathrm{ppbv}$ with an $r^{2}$ value of 0.99 . Although the value of $r^{2}$ has a limited meaning owing to the small number of samples, this might be an indication that, despite the analysis taking place within 5 weeks of the flight and dichloromethane being found to decrease with storage time in HIRES canisters, results may still reflect initial mixing ratios. If the decrease rate was the same for all tropospheric samples, the correlation of dichloromethane with $\mathrm{CO}$ might still persist even if mixing ratios of dichloromethane have decreased. A similar behaviour was found for tetrachloroethene and trichloromethane, as well as for the tropospheric samples for trichloroethene and dibromochloromethane. The latter compound was below its detection limit in all stratospheric samples, and trichloroethene was below its detection limit in several of them.

\section{Conclusions}

In order to assess the potential of halocarbon analysis from samples collected with the HIRES unit from the CARIBIC instrument package, the sample collection unit was intensively tested, focusing on compound stability in the stainlesssteel canisters and the influence of ozone. Sampling during CARIBIC flights takes place in the upper troposphere and the lowermost stratosphere, with ozone mixing ratios of up to several hundred parts per billion by volume. Therefore samples were pressurized with a mixture of a dry standard gas, containing typical tropospheric mixing ratios of a wide range of halogenated hydrocarbons, and synthetic air. The synthetic air could be enriched in ozone by passing an ozonegenerating UV lamp. Final ozone mixing ratios were estimated to range from 400 to $600 \mathrm{ppbv}$. This is representative of the mixing ratios typically encountered at flight levels in the lowermost stratosphere. Several short-lived halocarbons were found to be depleted in canisters pressurized in the pres-
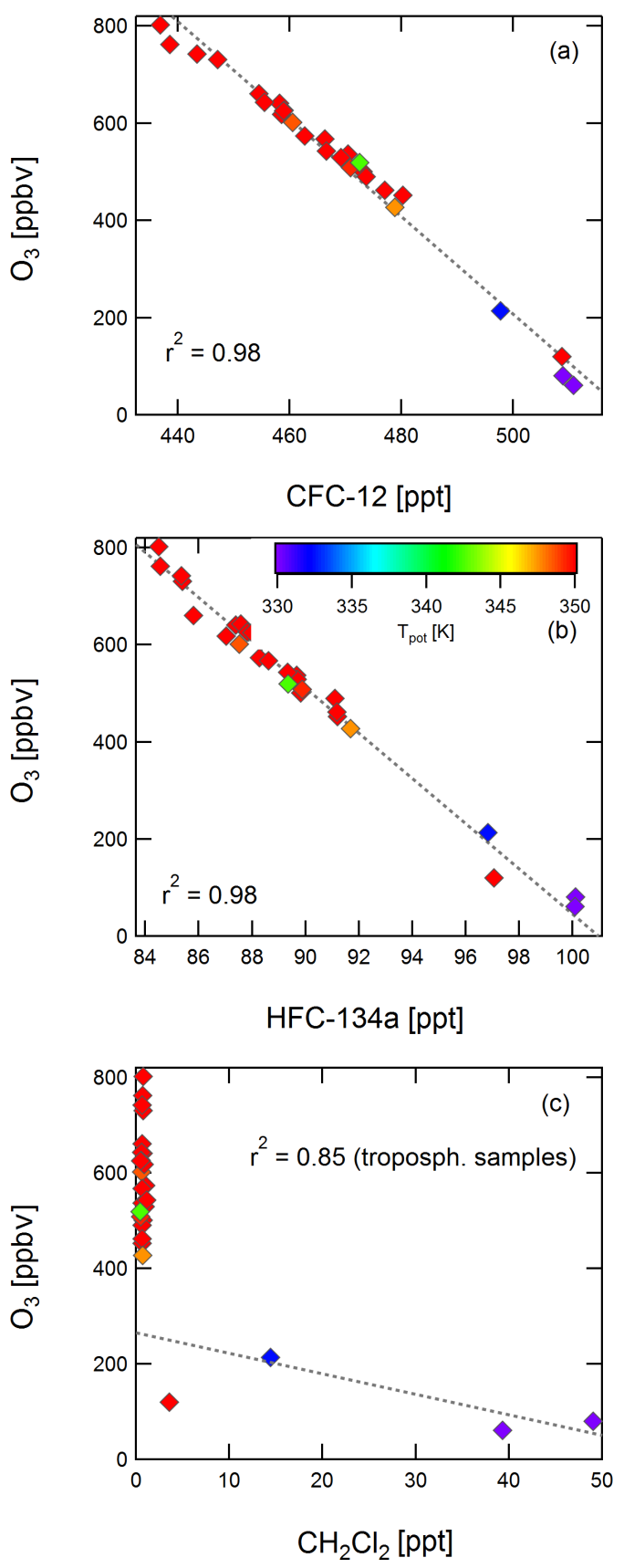

Figure 6. Correlation of CFC-12 (a), HFC-134a (b), and dichloromethane (c) with ozone. Colour coding is by potential temperature. Values of $r^{2}$ are given for the correlation of all samples for CFC-12 and HFC-134a and for three tropospheric samples in the case of dichloromethane.

ence of ozone. COS was found to exhibit higher mixing ratios in this case.

In one experiment, samples were analysed $1 \mathrm{~d}$ after pressurization and again after a storage time of 1 week. While bromomethane and chloromethane were found to have already grown in this short period, tribromomethane 

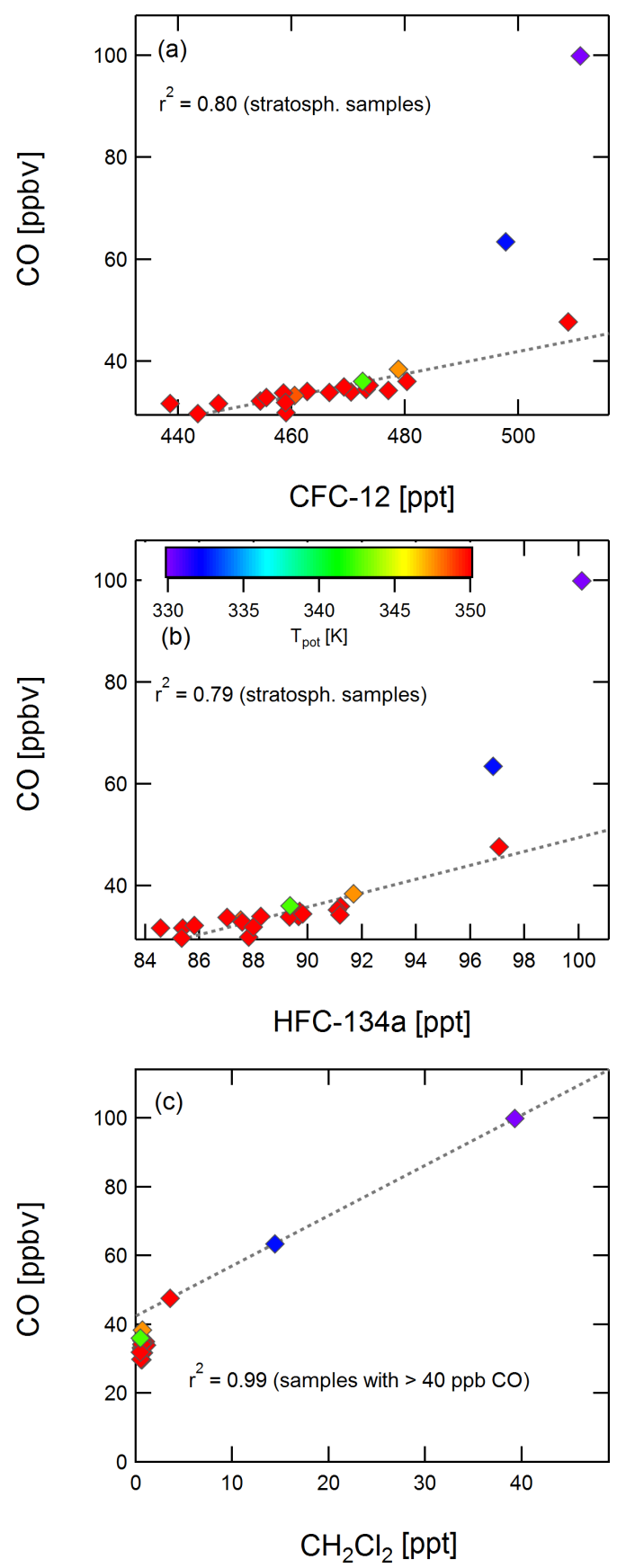

Figure 7. Correlation of CFC-12 (a), HFC-134a (b), and dichloromethane (c) with CO. Colour coding is by potential temperature. Values of $r^{2}$ are given for the correlation of stratospheric samples for CFC-12 and HFC-134a and for three samples with a $\mathrm{CO}$ mixing ratio above $40 \mathrm{ppb}$ in the case of dichloromethane.

and trichloroethene had decreased; tetrachloromethane was found to be stable, but its mixing ratio was significantly below the value expected. Of the 28 compounds investigated, 23 were found to be stable over storage of up to 1 week.

This changed in the long-term stability test, which was conducted in several time steps with periods of up to $57 \mathrm{~d}$. All compounds influenced by high levels of ozone were found to show the same behaviour (decreasing or increasing) during the long-term test. In addition, dichloromethane, trichloromethane, tetrachloroethene, tetrachloromethane, and bromochloromethane also showed a tendency to decrease after storage for more than 2 weeks. HFC152a, HFC-23, and Halon 1301 started to increase significantly. The tests showed that reliable measurement results for a number of halogenated tracers can only be achieved if measurements are performed within a few days of a flight. If this is not possible (which for CARIBIC samples is often the case, as they circulate between several laboratories at different institutions), results must be interpreted with care.

Measurements of samples from a CARIBIC flight in March 2018 that took place about 5 weeks after the flight confirmed the results from the stability tests. Mixing ratios of compounds found to decrease in the stability tests were in general very low, often below their respective detection limits. Additionally the results of the ozone test were confirmed, as mixing ratios of compounds found to be sensitive to ozone were low in canisters sampled in the stratosphere at high ozone mixing ratios. With the current HIRES unit it is not possible to study aspects such as the vertical gradients of mixing ratios above the tropopause for short-lived species. Compounds that had grown during the storage test were not evaluated.

Currently, we are in the process of constructing a second high-resolution air sampler for use inside the CARIBIC container. Based on the measurements presented here, close attention will be given to the manufacturing of the stainlesssteel cylinders, which will be made of electropolished stainless-steel foil, and welding will be performed under vacuum. In contrast to the canisters tested here, which were microplasma welded from similar stainless-steel foil that was not electropolished, we expect to obtain cleaner inside surfaces and cleaner welding seams. During the construction of the new sampling unit, more stability tests like those presented here will be performed.

Data availability. Data are available from the corresponding author upon individual request.

Author contributions. TS, AKB, and AE designed and performed the storage experiments. TS, AKB, and ER performed the data analysis. CAMB designed and constructed the HIRES unit. JW coordinated the HIRES handling and scientific deployment. AZ coordinated the CARIBIC project. TS wrote the first draft of the manuscript. All co-authors took part in the discussion of the results and contributed to the paper.

Competing interests. The authors declare that they have no conflict of interest. 
Acknowledgements. The authors acknowledge the contribution of technical staff who perform regular maintenance of the CARIBIC container and handle the air sampling unit. We would also like to thank Martin Vollmer (EMPA) for calibration of the laboratory standard and Laurin Merkel for drawing the HIRES unit.

Review statement. This paper was edited by Tim Arnold and reviewed by two anonymous referees.

\section{References}

Adcock, K. E., Reeves, C. E., Gooch, L. J., Leedham Elvidge, E. C., Ashfold, M. J., Brenninkmeijer, C. A. M., Chou, C., Fraser, P. J., Langenfelds, R. L., Mohd Hanif, N., O’Doherty, S., Oram, D. E., Ou-Yang, C.-F., Phang, S. M., Samah, A. A., Röckmann, T., Sturges, W. T., and Laube, J. C.: Continued increase of CFC$113 \mathrm{a}\left(\mathrm{CCl}_{3} \mathrm{CF}_{3}\right)$ mixing ratios in the global atmosphere: emissions, occurrence and potential sources, Atmos. Chem. Phys., 18, 4737-4751, https://doi.org/10.5194/acp-18-4737-2018, 2018.

Apel, E. C., Hills, A. J., Lueb, R., Zindel, S., Eisele, S., and Riemer, D. D.: A fast-GC/MS system to measure $\mathrm{C}_{2}$ to $\mathrm{C}_{4}$ carbonyls and methanol aboard aircraft, J. Geophys. Res.-Atmos., 108, 8794, https://doi.org/10.1029/2002JD003199, 2003.

Baker, A. K., Slemr, F., and Brenninkmeijer, C. A. M.: Analysis of non-methane hydrocarbons in air samples collected aboard the CARIBIC passenger aircraft, Atmos. Meas. Tech., 3, 311-321, https://doi.org/10.5194/amt-3-311-2010, 2010.

Baker, A. K., Sauvage, C., Thorenz, U. R., van Velthoven, P., Oram, D. E., Zahn, A., Brenninkmeijer, C. A. M., and Williams, J.: Evidence for strong, widespread chlorine radical chemistry associated with pollution outflow from continental Asia, Sci. Rep., 6, 36821, https://doi.org/10.1038/srep36821, 2016.

Batterman, S. A., Zhang, G.-Z., and Baumann, M.: Analysis and stability of aldehydes and terpenes in electropolished canisters, Atmos. Environ., 32, 1647-1655, https://doi.org/10.1016/S13522310(97)00417-2, 1998.

Bourtsoukidis, E., Helleis, F., Tomsche, L., Fischer, H., Hofmann, R., Lelieveld, J., and Williams, J.: An aircraft gas chromatograph-mass spectrometer System for Organic Fast Identification Analysis (SOFIA): design, performance and a case study of Asian monsoon pollution outflow, Atmos. Meas. Tech., 10, 5089-5105, https://doi.org/10.5194/amt-105089-2017, 2017.

Brenninkmeijer, C. A. M., Crutzen, P., Boumard, F., Dauer, T., Dix, B., Ebinghaus, R., Filippi, D., Fischer, H., Franke, H., Frie $\beta$, U., Heintzenberg, J., Helleis, F., Hermann, M., Kock, H. H., Koeppel, C., Lelieveld, J., Leuenberger, M., Martinsson, B. G., Miemczyk, S., Moret, H. P., Nguyen, H. N., Nyfeler, P., Oram, D., O’Sullivan, D., Penkett, S., Platt, U., Pupek, M., Ramonet, M., Randa, B., Reichelt, M., Rhee, T. S., Rohwer, J., Rosenfeld, K., Scharffe, D., Schlager, H., Schumann, U., Slemr, F., Sprung, D., Stock, P., Thaler, R., Valentino, F., van Velthoven, P., Waibel, A., Wandel, A., Waschitschek, K., Wiedensohler, A., Xueref-Remy, I., Zahn, A., Zech, U., and Ziereis, H.: Civil Aircraft for the regular investigation of the atmosphere based on an instrumented container: The new CARIBIC system, Atmos. Chem. Phys., 7, 4953-4976, https://doi.org/10.5194/acp-7-4953-2007, 2007.
Engel, A., Rigby, M. L. A., Burkholder, J., Fernandez, R., Froidevaux, L., Hall, B., Hossaini, R., Saito, T., Vollmer, B., and Yao, B.: Update on Ozone-Depleting Substances (ODSs) and Other Gases of Interest to the Montreal Protocol, in: Scientific Assessment of Ozone Depletion: 2018, Global Ozone Research and Monitoring Project-Report No. 58, Chapter 1, World Meteorological Organization, Geneva, Switzerland, 1.1-1.87, 2018.

Hoker, J., Obersteiner, F., Bönisch, H., and Engel, A.: Comparison of GC/time-of-flight MS with GC/quadrupole MS for halocarbon trace gas analysis, Atmos. Meas. Tech., 8, 2195-2206, https://doi.org/10.5194/amt-8-2195-2015, 2015.

Hsieh, C.-C., Horng, S.-H., and Liao, P.-N.: Stability of Trace-level VOLatile Organic Compounds Stored in Canisters and Tedlar Bags, Aerosol Air Qual. Res., 3, 17-28, https://doi.org/10.4209/aaqr.2003.06.0003, 2003.

Jensen, E. J., Pfister, L., Jordan, D. E., Bui, T. V., Ueyama, R., Singh, H. B., Thornberry, T. D., Rollins, A. W., Gao, R.-S., Fahey, D. W., Rosenlof, K. H., Elkins, J. W., Diskin, G. S., DiGangi, J. P., Lawson, R. P., Woods, S., Atlas, E. L., Navarro Rodriguez, M. A., Wofsy, S. C., Pittman, J., Bardeen, C. G., Toon, O. B., Kindel, B. C., Newman, P. A., McGill, M. J., Hlavka, D. L., Lait, L. R., Schoeberl, M. R., Bergman, J. W., Selkirk, H. B., Alexander, M. J., Kim, J.-E., Lim, B. H., Stutz, J., and Pfeilsticker, K.: The NASA Airborne Tropical Tropopause Experiment: High-Altitude Aircraft Measurements in the Tropical Western Pacific, B. Am. Meteorol. Soc., 98, 129-143, https://doi.org/10.1175/BAMS-D-14-00263.1, 2017.

Keber, T., Bönisch, H., Hartick, C., Hauck, M., Lefrancois, F., Obersteiner, F., Ringsdorf, A., Schohl, N., Schuck, T., Hossaini, R., Graf, P., Jöckel, P., and Engel, A.: Bromine from short-lived source gases in the Northern Hemisphere UTLS, Atmos. Chem. Phys. Discuss., https://doi.org/10.5194/acp-2019-796, in review, 2019.

Laube, J. C., Martinerie, P., Witrant, E., Blunier, T., Schwander, J., Brenninkmeijer, C. A. M., Schuck, T. J., Bolder, M., Röckmann, T., van der Veen, C., Bönisch, H., Engel, A., Mills, G. P., Newland, M. J., Oram, D. E., Reeves, C. E., and Sturges, W. T.: Accelerating growth of HFC-227ea (1,1,1,2,3,3,3-heptafluoropropane) in the atmosphere, Atmos. Chem. Phys., 10, 5903-5910, https://doi.org/10.5194/acp-10-5903-2010, 2010.

Laube, J. C., Hogan, C., Newland, M. J., Mani, F. S., Fraser, P. J., Brenninkmeijer, C. A. M., Martinerie, P., Oram, D. E., Röckmann, T., Schwander, J., Witrant, E., Mills, G. P., Reeves, C. E., and Sturges, W. T.: Distributions, long term trends and emissions of four perfluorocarbons in remote parts of the atmosphere and firn air, Atmos. Chem. Phys., 12, 4081-4090, https://doi.org/10.5194/acp-12-4081-2012, 2012.

Laube, J. C., Mohd Hanif, N., Martinerie, P., Gallacher, E., Fraser, P. J., Langenfelds, R., Brenninkmeijer, C. A. M., Schwander, J., Witrant, E., Wang, J.-L., Ou-Yang, C.-F., Gooch, L. J., Reeves, C. E., Sturges, W. T., and Oram, D. E.: Tropospheric observations of CFC-114 and CFC-114a with a focus on long-term trends and emissions, Atmos. Chem. Phys., 16, 15347-15358, https://doi.org/10.5194/acp-16-15347-2016, 2016.

Leedham Elvidge, E. C., Oram, D. E., Laube, J. C., Baker, A. K., Montzka, S. A., Humphrey, S., O'Sullivan, D. A., and Brenninkmeijer, C. A. M.: Increasing concentrations of dichloromethane, $\mathrm{CH}_{2} \mathrm{Cl}_{2}$, inferred from CARIBIC air sam- 
ples collected 1998-2012, Atmos. Chem. Phys., 15, 1939-1958, https://doi.org/10.5194/acp-15-1939-2015, 2015.

Lerner, B. M., Gilman, J. B., Aikin, K. C., Atlas, E. L., Goldan, P. D., Graus, M., Hendershot, R., Isaacman-VanWertz, G. A., Koss, A., Kuster, W. C., Lueb, R. A., McLaughlin, R. J., Peischl, J., Sueper, D., Ryerson, T. B., Tokarek, T. W., Warneke, C., Yuan, B., and de Gouw, J. A.: An improved, automated whole air sampler and gas chromatography mass spectrometry analysis system for volatile organic compounds in the atmosphere, Atmos. Meas. Tech., 10, 291-313, https://doi.org/10.5194/amt-10-2912017, 2017.

Li, M., Karu, E., Brenninkmeijer, C., Fischer, H., Lelieveld, J., and Williams, J.: Tropospheric $\mathrm{OH}$ and stratospheric $\mathrm{OH}$ and $\mathrm{Cl}$ concentrations determined from $\mathrm{CH} 4, \mathrm{CH} 3 \mathrm{Cl}$, and $\mathrm{SF} 6$ measurements, npj Climate and Atmospheric Science, 1, 29, https://doi.org/10.1038/s41612-018-0041-9, 2018.

Machida, T., Matsueda, H., Sawa, Y., Nakagawa, Y., Hirotani, K., Kondo, N., Goto, K., Nakazawa, T., Ishikawa, K., and Ogawa, T.: Worldwide Measurements of Atmospheric $\mathrm{CO}_{2}$ and Other Trace Gas Species Using Commercial Airlines, J. Atmos. Ocean. Tech., 25, 1744-1754, https://doi.org/10.1175/2008JTECHA1082.1, 2008.

Navarro, M. A., Atlas, E. L., Saiz-Lopez, A., Rodriguez-Lloveras, X., Kinnison, D. E., Lamarque, J.-F., Tilmes, S., Filus, M., Harris, N. R. P., Meneguz, E., Ashfold, M. J., Manning, A. J., Cuevas, C. A., Schauffler, S. M., and Donets, V.: Airborne measurements of organic bromine compounds in the Pacific tropical tropopause layer, P. Natl. Acad. Sci. USA, 112, 13789-13793, https://doi.org/10.1073/pnas.1511463112, 2015.

Obersteiner, F., Bönisch, H., Keber, T., O’Doherty, S., and Engel, A.: A versatile, refrigerant- and cryogen-free cryofocusingthermodesorption unit for preconcentration of traces gases in air, Atmos. Meas. Tech., 9, 5265-5279, https://doi.org/10.5194/amt9-5265-2016, 2016.

Ochiai, N., Tsuji, A., Nakamura, N., Daishima, S., and Cardin, D. B.: Stabilities of 58 volatile organic compounds in fused-silica-lined and SUMMA polished canisters under various humidified conditions, J. Environ. Monit., 4, 879-889, https://doi.org/10.1039/B209210G, 2002.

Oram, D. E., Ashfold, M. J., Laube, J. C., Gooch, L. J., Humphrey, S., Sturges, W. T., Leedham-Elvidge, E., Forster, G. L., Harris, N. R. P., Mead, M. I., Samah, A. A., Phang, S. M., Ou-Yang, C.-F., Lin, N.-H., Wang, J.-L., Baker, A. K., Brenninkmeijer, C. A. M., and Sherry, D.: A growing threat to the ozone layer from short-lived anthropogenic chlorocarbons, Atmos. Chem. Phys., 17, 11929-11941, https://doi.org/10.5194/acp-17-119292017, 2017.

Petzold, A., Thouret, V., Gerbig, C., Zahn, A., Brenninkmeijer, C. A. M., Gallagher, M., Hermann, M., Pontaud, M., Ziereis, H., Boulanger, D., Marshall, J., Nédélec, P., Smit, H. G. J., Friess, U., Flaud, J.-M., Wahner, A., Cammas, J.-P., Volz-Thomas, A., and TEAM, I.: Global-scale atmosphere monitoring by in-service aircraft - current achievements and future prospects of the European Research Infrastructure IAGOS, Tellus B, 67, 28452, https://doi.org/10.3402/tellusb.v67.28452, 2015.
Sala, S., Bönisch, H., Keber, T., Oram, D. E., Mills, G., and Engel, A.: Deriving an atmospheric budget of total organic bromine using airborne in situ measurements from the western Pacific area during SHIVA, Atmos. Chem. Phys., 14, 6903-6923, https://doi.org/10.5194/acp-14-6903-2014, 2014.

Scharffe, D., Slemr, F., Brenninkmeijer, C. A. M., and Zahn, A.: Carbon monoxide measurements onboard the CARIBIC passenger aircraft using UV resonance fluorescence, Atmos. Meas. Tech., 5, 1753-1760, https://doi.org/10.5194/amt-5-1753-2012, 2012.

Schuck, T. J., Brenninkmeijer, C. A. M., Slemr, F., Xueref-Remy, I., and Zahn, A.: Greenhouse gas analysis of air samples collected onboard the CARIBIC passenger aircraft, Atmos. Meas. Tech., 2, 449-464, https://doi.org/10.5194/amt-2-449-2009, 2009.

Schuck, T. J., Ishijima, K., Patra, P. K., Baker, A. K., Machida, T., Matsueda, H., Sawa, Y., Umezawa, T., Brenninkmeijer, C. A. M., and Lelieveld, J.: Distribution of methane in the tropical upper troposphere measured by CARIBIC and CONTRAIL aircraft, J. Geophys. Res.-Atmos., 117, D19304, https://doi.org/10.1029/2012JD018199, 2012.

Schuck, T. J., Lefrancois, F., Gallmann, F., Wang, D., Jesswein, M., Hoker, J., Bönisch, H., and Engel, A.: Establishing long-term measurements of halocarbons at Taunus Observatory, Atmos. Chem. Phys., 18, 16553-16569, https://doi.org/10.5194/acp-1816553-2018, 2018.

Sturges, W. T., Oram, D. E., Laube, J. C., Reeves, C. E., Newland, M. J., Hogan, C., Martinerie, P., Witrant, E., Brenninkmeijer, C. A. M., Schuck, T. J., and Fraser, P. J.: Emissions halted of the potent greenhouse gas SF5CF3, Atmos. Chem. Phys., 12, 36533658, https://doi.org/10.5194/acp-12-3653-2012, 2012.

Wisher, A., Oram, D. E., Laube, J. C., Mills, G. P., van Velthoven, P., Zahn, A., and Brenninkmeijer, C. A. M.: Very short-lived bromomethanes measured by the CARIBIC observatory over the North Atlantic, Africa and Southeast Asia during 2009-2013, Atmos. Chem. Phys., 14, 3557-3570, https://doi.org/10.5194/acp14-3557-2014, 2014.

Wofsy, S. C.: HIAPER Pole-to-Pole Observations (HIPPO): finegrained, global-scale measurements of climatically important atmospheric gases and aerosols, P. Roy. Soc. A-Math. Phy., 369, 2073-2086, https://doi.org/10.1098/rsta.2010.0313, 2011.

Zahn, A., Weppner, J., Widmann, H., Schlote-Holubek, K., Burger, B., Kühner, T., and Franke, H.: A fast and precise chemiluminescence ozone detector for eddy flux and airborne application, Atmos. Meas. Tech., 5, 363-375, https://doi.org/10.5194/amt-5363-2012, 2012. 